\title{
Mummies reveal that clogged arteries plagued the ancient world
}

\section{Scans suggest that there's more to heart disease than a modern diet.}

Jo Marchant

11 March 2013

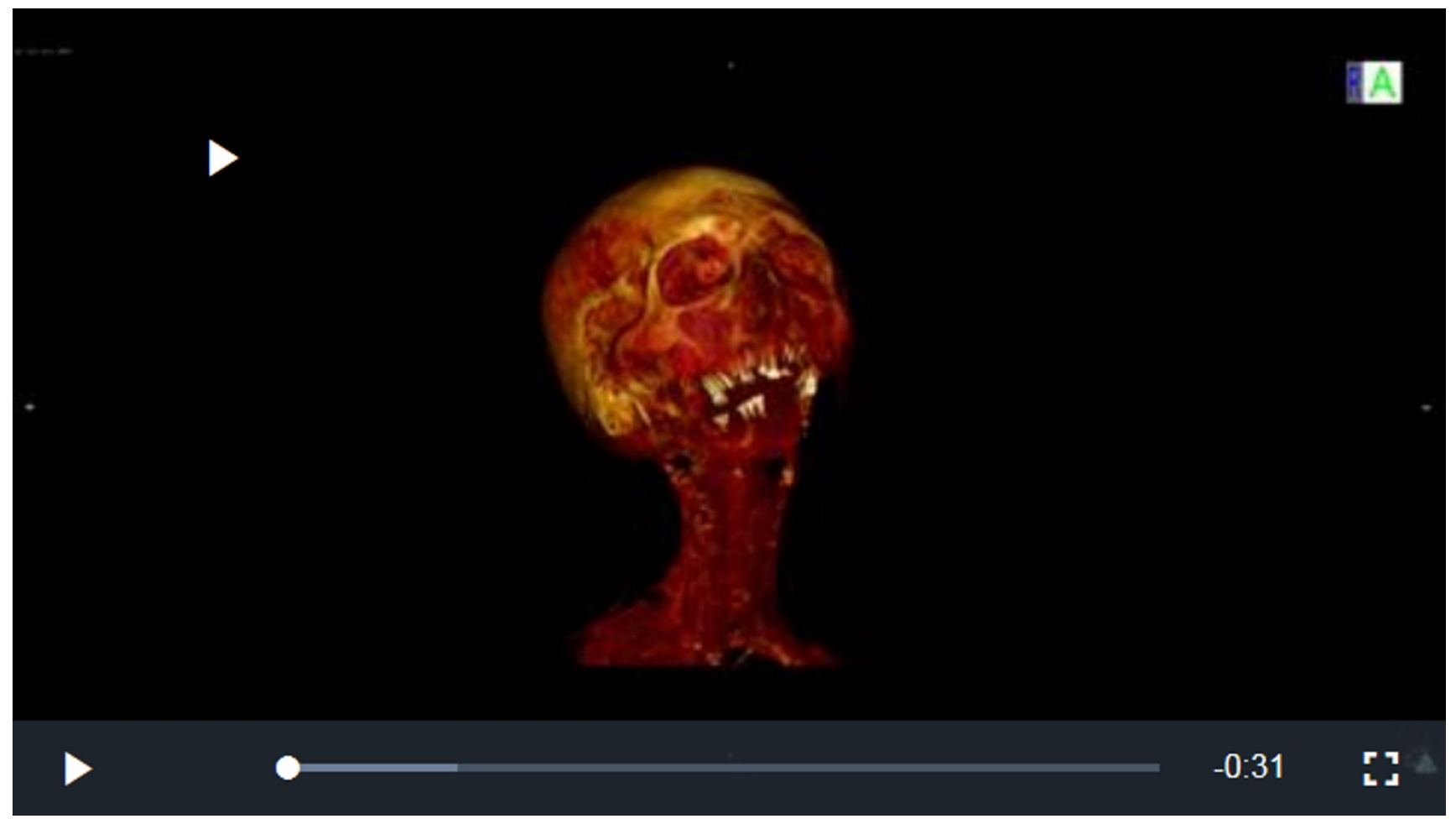

Clogged arteries are seen as the quintessential symptom of an unhealthy modern lifestyle. But the condition was common across the ancient world, even among active hunter-gatherers with no access to junk food, a study of mummies has found.

"There's a belief that if we go back in time, everything's going to be OK," says cardiologist Greg Thomas of the University of California, Irvine, a senior member of the study team. "But these mummies still have coronary artery disease." The paper is published in the current issue of The Lancet ${ }^{1}$.

\section{Blocked arteries}

In atherosclerosis, arteries become narrowed and hardened by plaques - made up of cholesterol and immune cells called macrophages - that build up in their walls. The condition can lead to heart attacks, stroke and other cardiovascular diseases and is the leading cause of death in the developed world.

A lack of exercise and a diet high in saturated fat — both of which increase levels of 'bad' cholesterol in the blood — are thought to increase the risk of plaques building up. This has led to the suggestion that to avoid heart disease we should try to live more like our hunter-gatherer ancestors, on a diet of unprocessed foods high in protein and unsaturated fats ${ }^{2}$.

To find out if that's really true, Thomas and his colleagues performed CT scans on 137 mummies from four very different ancient populations: Egyptian, Peruvian, the Ancestral Puebloans of southwest America and the Unangans of the Aleutian Islands in Alaska. The Egyptians were artificially embalmed, whereas the other bodies were preserved naturally by very dry or very cold conditions.

The four groups had different lifestyles — the Ancestral Puebloans were forager-farmers, for example, whereas the Unangan were hunter-gatherers with an exclusively marine diet.

The researchers checked the mummies' scans for calcified plaques in the wall of an artery or along the expected course of an artery. They diagnosed probable or definite atherosclerosis in 47 (34\%) of the 137 mummies, and in all four populations, ranging from $25 \%$ of 
the 51 ancient Peruvians to $60 \%$ of the five Unangans.

\section{Ancient disease}

The researchers say that they found a level of disease equivalent to that in modern populations — a result Thomas describes as "a shock".

The team previously had found atherosclerosis in a population of ancient Egyptians ${ }^{3}$, but experts, including Rosalie David at the KNH Centre for Biomedical Egyptology in Manchester, UK, argued that these were elite individuals, who probably ate a rich diet rivalling that of modern gluttons ${ }^{4}$.

"Now we've scanned the common man and woman and they've got the same disease," says Thomas. Rather than excess cholesterol, he suggests that high levels of inflammation - caused by smoke inhalation or chronic infection, for instance - may have triggered the disease in these individuals.

Michael Rosenfeld at the University of Washington, Seattle, who studies the pathology of atherosclerosis, agrees that such factors can accelerate the course of the disease. But he points out that in animal studies, atherosclerosis does not develop without high levels of fat in the blood - whether as the result of bad diet or of bad genes.

He adds that the plaques seen in the mummies might have been caused by kidney disease or osteoporosis, rather than by atherosclerosis. "I still strongly believe that modern lifestyles have a lot to do with the development of atherosclerosis," he says.

But Thomas says that cardiovascular disease should not now be seen as simply a consequence of an unhealthy lifestyle. "We've oversold the ability to stop heart disease," he says. "We can slow it down, but to think we can prevent it is unrealistic."

Nature | doi:10.1038/nature.2013.12568

\section{References}

1. Thompson, R. C. et al. The Lancet http://dx.doi.org/10.1016/S0140-6736(13)60598-X(2013).

2. O'Keefe, J. H. Jr \& Cordain, L. Mayo Clin. Proc. 79, 101-108 (2004).

3. Allam, A. H., Thompson, R. C., Wann, L. S., Miyamoto, M. L. \& Thomas, G. S. J. Am. Med. Assoc. 302, 2091-2094 (2009).

4. David, A. R., Kershaw, A. \& Heagerty, A. The Lancet 375, 718-719 (2010). 